\title{
Web Interface for Modeling Fog Oil Dispersion During Training
}

Robert C. Lozar

Fog Oil Release Test at Fort Leonard Wood MO Vertically Integrated Horizontal Slice
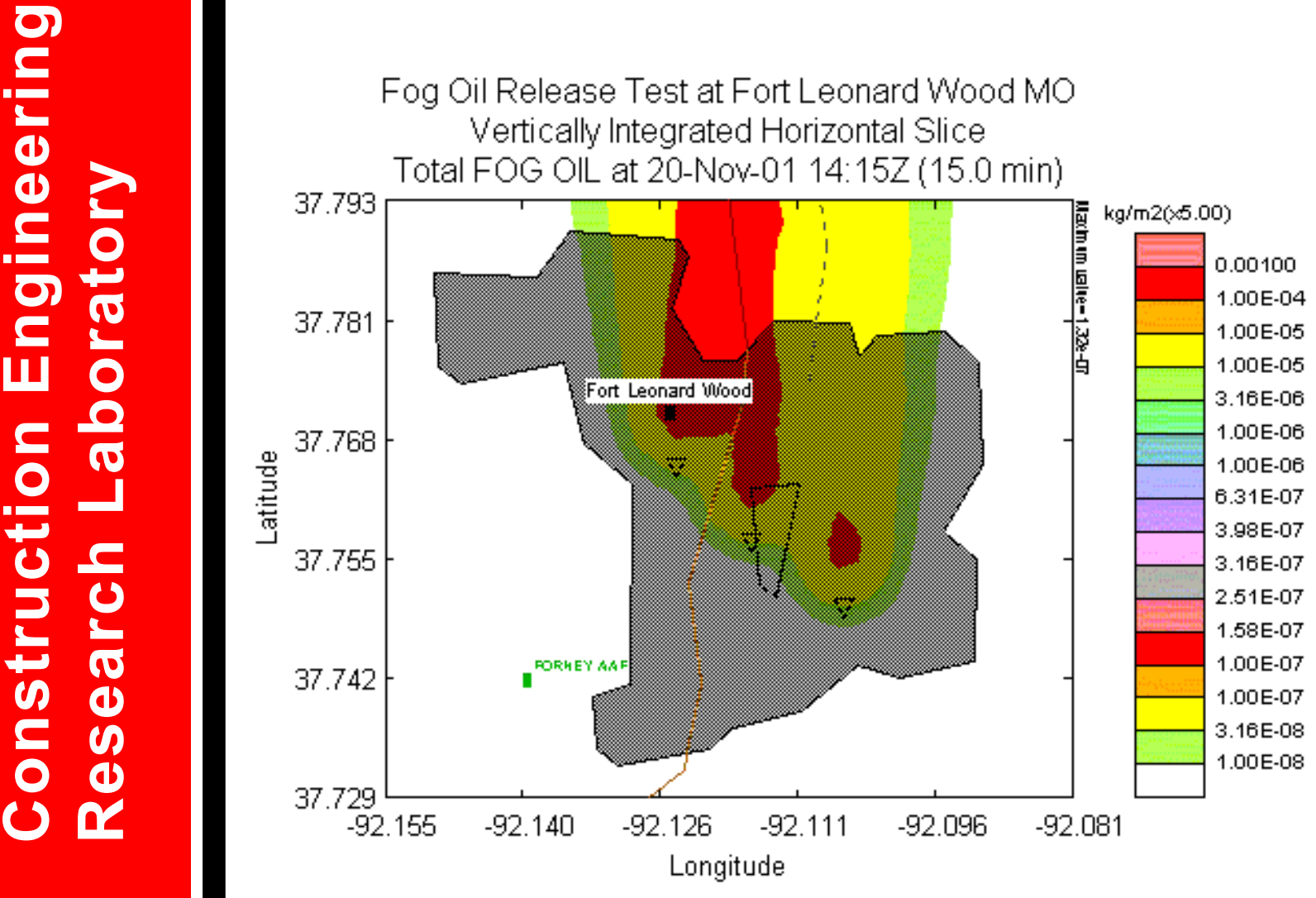


\section{Foreword}

This study was conducted in support of two projects. The first was for the Strategic Environmental Research and Development Program (SERDP) under project, CS-507 "Threatened, Endangered, and Sensitive Resources: Smokes and Obscurants"; The Technical Monitor was Dr. Robert Holst, SERDP Program Manager. The second was for the 622720A896 direct-funded project, Work Unit CNN-TO21, "Smoke/Obscurant Threshold Extrapolated to User Primary Species."

The work was performed by the Ecological Processes Branch (CN-N) of the Installations Division (CN), Construction Engineering Research Laboratory (CERL). The CERL Principal Investigator was Dr. Harold E. Balbach. The technical editor was Gloria J. Wienke, Information Technology Laboratory. Stephen Hodapp is Chief, CEERD-CN-N, and Dr. John T. Bandy is Chief, CEERD-CN. The associated Technical Director was Dr. William D. Severinghaus, CEERD-CV-T. The Director of CERL is Dr. Alan W. Moore.

CERL is an element of the U.S. Army Engineer Research and Development Center (ERDC), U.S. Army Corps of Engineers. The Commander and Executive Director of ERDC is COL John Morris III, EN and the Director of ERDC is Dr. James R. Houston.

DISCLAIMER: The contents of this report are not to be used for advertising, publication, or promotional purposes. Citation of trade names does not constitute an official endorsement or approval of the use of such commercial products. All product names and trademarks cited are the property of their respective owners. The findings of this report are not to be construed as an official Department of the Army position unless so designated by other authorized documents.

DESTROY THIS REPORT WHEN IT IS NO LONGER NEEDED. DO NOT RETURN IT TO THE ORIGINATOR. 


\section{Contents}

Foreword

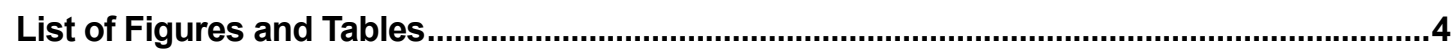

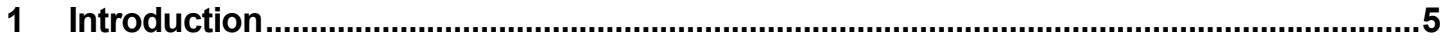

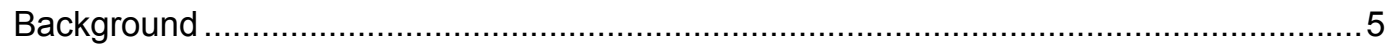

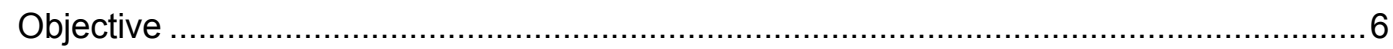

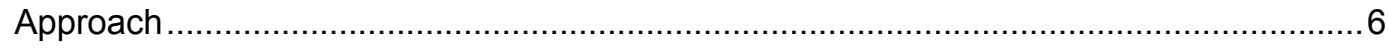

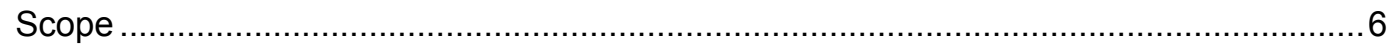

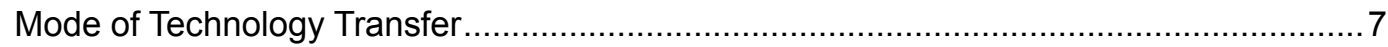

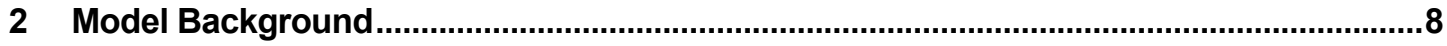

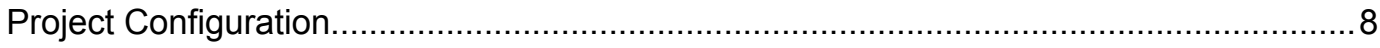

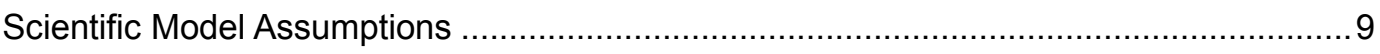

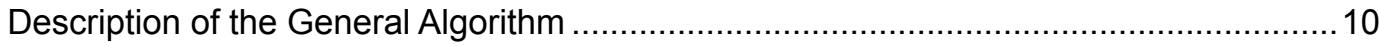

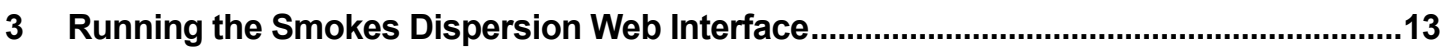

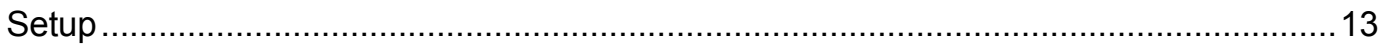

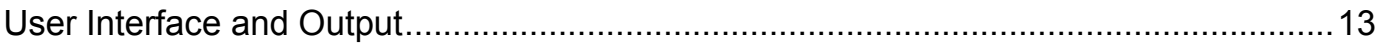

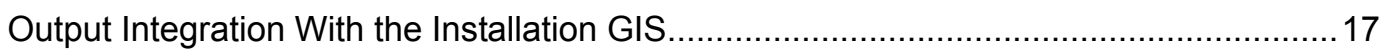

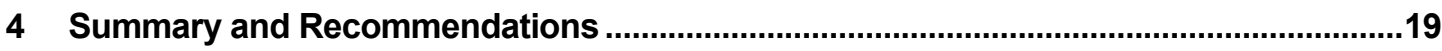

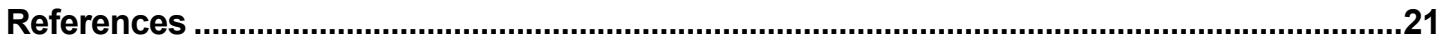

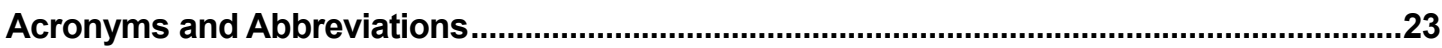

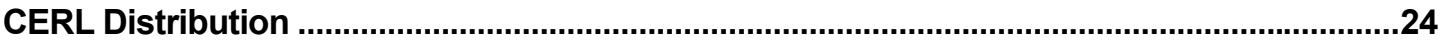

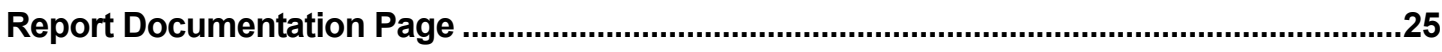




\section{List of Figures}

\section{Figures}

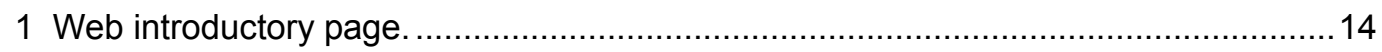

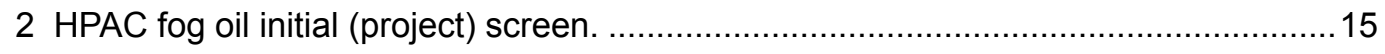

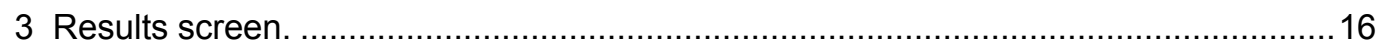

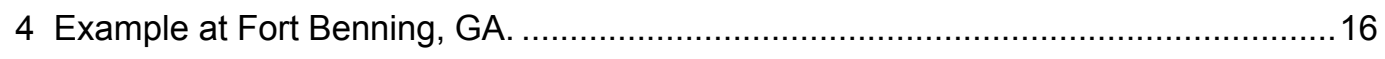

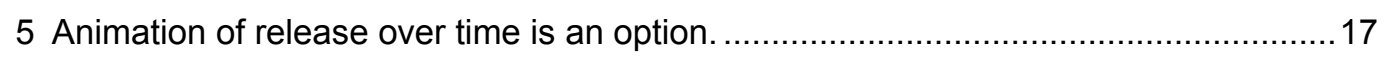

6 Integrated into GIS format with TES locations at Fort Stewart, GA.......................... 18 


\section{Introduction}

\section{Background}

To confuse and deceive enemies, forces have used obscurants in their military campaigns for thousands of years. Burning of damp straw was a common method of smoking enemy positions as early as 2000 B.C. The use of large-area smokes increased dramatically during World War II and set the stage for the current use of smokes in military exercises.

Obscurants are man-made or naturally occurring particles suspended in the air. They block the transmission of a particular part of the electromagnetic spectrum. Fog, mist, dust, and smoke are all examples of obscurants. Military smoke is a man-made obscurant produced by burning or vaporizing some product. Fog oil is the material most commonly used in smoke operations during training exercises (Getz et al. 1996). Standard Grade Fuel No. 2 (SGF-2) is currently the fog oil of choice for year-round obscuration needs. Fog oil is vaporized by a mechanical generator (Field Manual [FM] 3-50); smoke-generating engines are also used to produce smoke. The oil portion quickly condenses when it comes in contact with the air; this produces the liquid drops that make up the obscuring smoke (Driver et al. 1993).

Fog oil used in smoke production contains many hydrocarbon compounds, most of which are present in quantities of less than 0.1 percent. However, there is concern that the residue materials may affect wildlife on military installations where soldiers are trained in the correct usage of these materials. In the United States, this is particularly important when the affected species is classified as threatened or endangered, because special care must be taken to comply with the Endangered Species Act.

The Strategic Environmental Research and Development Program (SERDP) is a partnership of the Department of Defense (DoD), Department of Energy (DOE), and Environmental Protection Agency (EPA). To help the military comply with environmental laws, SERDP funded a project for the Engineer Research and Development Center's Construction Engineering Research Laboratory (ERDC/CERL) to provide an objective computer-based modeling procedure to ensure that actions taken at U.S. military training installations will have little or 
no effect on identified Threatened and Endangered Species (TES). As a first step in 1998, a web-based plume dispersion demonstration was implemented in response to the SERDP Milestone 5.6.0, "Incorporate improved fog oil dispersion model into existing GIS system." This was the Gaussian Plume Model based on a UNIX operating system configuration, available over the local network. As a second step, a more robust modeling method was to be adopted in order to answer the stated SERDP need (Milestone 5.11.0), "Develop a more specific method for fog oil analysis." Several avenues to implement a web-based fog oil modeling capability were investigated. In 2001, additional direct Army conservation research funds were used to implement the web-based interface discussed in this report.

\section{Objective}

The objective of this research is to describe and document (1) the functions of the web interface for modeling fog oil dispersion during training, and (2) how it can be implemented and run at a military installation.

\section{Approach}

As a first step in 1998, a web-based plume dispersion model demonstration was implemented. The current research documents the second step of developing a more specific, web-based method for fog oil analysis. The ERDC/CERL researcher surveyed the available models and selected the Hazard Protection and Assessment Capability (HPAC) program.

\section{Scope}

It is assumed that the user will be able to acquire the Hazard Prediction and Assessment Capability program available from the Defense Threat Reduction Agency (DTRA). This document does not describe in detail how that program works; that information is available in selected references provided. 


\section{Mode of Technology Transfer}

This report represents the documentation of the web smokes model. The HPAC model is available from DTRA. ${ }^{1}$ The web adaptation is available from ERDC/CERL in Champaign, IL. ${ }^{2}$

This report will be made accessible through the World Wide Web (WWW) at URL: http://www.cecer.army.mil/

1 Defense Threat Reduction Agency/CPWE, 6810 Telegraph Road, Alexandria, VA 22310-3389; telephone: (703) 325-7143; FAX: (703) 325-0398.

2 ERDC/CERL, ATTN: CN-N (Robert C. Lozar), PO Box 9005, Champaign, IL, 61822-9005; telephone: (217) $352-$ 6511, ext 6367; email: Robert.C.Lozar@erdc.usace.army.mil 


\section{Model Background}

\section{Project Configuration}

The military must act in accordance with public law. DoD must ensure that actions taken at U.S. military training installations will have no adverse effect on identified TES. ERDC/CERL has been developing the means of making sophisticated evaluations of Smokes and Obscurants (SO) dispersion, particularly from fog oil, more readily available to its users - military training lands managers. The problem the research needed to address is, "Just hours before using these materials, how does a trainer at an installation predict the possible correlation of obscurants (e.g., of fog oil-generated smoke) with TES present at an installation?" Since this question is dependent on the characteristics of weather, predictions made earlier than a few hours before the training action may not be accurate enough to comply with the requirements of oversight agencies.

This is a timely question because if Army SO training at installations has an effect on the TES, environmental regulators may not allow such training. ${ }^{3}$ Currently, some of the SO training mission in the Army is being transferred from Fort McClellan, AL, to Fort Leonard Wood, MO. To show good land and natural resource management responsibility to regulators in the State of Missouri (and thus obtain a permit to carry out SO training on the installation), an objective means of evaluating TES effects could be implemented at this installation (as others) and demonstrated to the regulators.

The new web-based model described here predicts the dispersion of the fog oil smoke. One of the guiding principals of this research effort was to use the best available technology rather than attempting to develop a new model. The web version is built on DTRA's HPAC program. HPAC runs on a desktop computer

\footnotetext{
3 Since this research on TES began, other studies (e.g., Driver et al. 2002) have shown that it is unlikely that fog oil has a negative effect on Red-cockaded Woodpeckers.
} 
with the MS Windows ${ }^{\circledR}{ }^{4}$ operating system. ERDC has implemented a HyperText Markup Language (HTML) web interface so HPAC is easy to use and can be accessed across the local area network (LAN). The web-based format allows for easy integration of additional new models as researchers in the dispersion field develop them. In fact, this is the second such model; the first (Lozar and Reinbold 2001) was based upon a Gaussian-plume dispersion algorithm.

The model was configured so that an installation trainer or natural resource specialist will be able to access the modeling capability with a web browser. The user will have several options available to run a fog-oil training scenario. The intent is that a user would be able to provide to the model the most current meteorological data and within seconds have available a prediction of the distribution of fog oil concentrations. The output would be useful for purposes of action planning and environmental documentation.

\section{Scientific Model Assumptions}

The intent of the work was to develop a linkage between a standard dispersion model and Geographic Information Systems (GIS) techniques that will allow for the input of installation-specific georeferenced data to predict the potential exposure of TES to an obscurant's spread at the installation.

For this initiative, the following assumptions were made:

- The work would be aimed specifically at SO (though many dispersion models existed, few deal specifically with SO).

- The dispersion model would be capable of predicting dispersion at the meso-scale level.

- The model configuration needs to deal with inputs that include: terrain, land cover, and meteorological data (points or complex MET [meteorological] data).

\footnotetext{
4 Citing product names does not imply endorsement by the U.S. Army Corps of Engineers or the Department of Defense.
} 
- The model configuration needs to exhibit a good deal of portability for application at different installations.

- The results of the model configuration should be available through a minimum configuration of a PC with Windows as the operating system.

- One result of the configuration is output mapped to a GIS.

- The configuration must calculate the result relatively quickly.

- The cost per implementation at a military installation should be minimal.

- The output must be in a format that can be made compatible with the military installation's GIS (if existing) so that updates to the TES files could easily be integrated into the resulting model configuration.

- The dispersion model interface implementation should be intuitive.

- The interface should be to an existing, robust dispersion model rather than one that ERDC/CERL independently developed.

Based on this guidance, ERDC/CERL did an evaluation of several options and came to the conclusion that no single configuration provided the support required (Lozar and Hanson January 1997). At this time, the discussion of a webbased configuration began. It quickly became clear that this configuration provided a unique set of advantages and so was adopted as the target direction in which to proceed.

\section{Description of the General Algorithm}

The HPAC Model assesses the dispersion of atmospheric concentrations downwind from point sources. The calculations are based on a Second-order Closure Integrated PUFF model (SCIPUFF) program (Sykes et al. 1996) within HPAC. The model can integrate terrain and land cover conditions into its calculations. It provides flexibility in input parameters for height, rate, temperature, and duration.

SCIPUFF is a LaGrangian puff dispersion model that uses a collection of Gaussian puffs to represent an arbitrary, three-dimensional time-dependent concentration. The diffusion parameterization is based on turbulence closure theory, providing a direct relationship between the predicted dispersion rate and 
turbulent velocity statistics of the wind field. In addition to the average concentration value, the closure model also provides a prediction of the statistical variance in the concentration field resulting from the random fluctuations in the wind field. The closure approach also provides a direct representation for the effect of averaging time. SCIPUFF has been validated against a number of laboratory and field experiments, demonstrating its usefulness. It has been recommended as an alternative model by the EPA; one that can be used on a case-by-case basis for regulatory applications.

The algorithm used by SCIPUFF provides a probabilistic prediction of the atmospheric dispersion and surface deposition processes, with the capability to model multidimensional, time-dependent wind fields. The release may be instantaneous, continuous, or moving. Uncertainty in the wind field, including both boundary-layer scale turbulent eddies and larger scale unknown variations, leads to a random component in the concentration field that requires at least the mean value and the standard deviation for a quantitative description. SCIPUFF uses turbulence closure theory to predict the concentration fluctuation variance as a function of the wind field uncertainty (Sykes, Lewellen, and Parker 1986; Sykes et al. 1993), and provides a probabilistic description of the resulting impact using a parameterized probability distribution function (Sykes, Lewellen, and Parker 1986). SCIPUFF includes a new dense gas model, consideration of precipitation washout, and the calculation of surface dose at elevations above the ground surface. Input may be performed using either of two options: operational or advanced modes.

The generalized SCIPUFF (Sykes and Gabruk 1997; Sykes et al. 1998; Sykes, Cerasoli, and Henn 1999) can deal with:

- Continuous, instantaneous, moving and stack sources

- Gaseous and particulate materials

- Buoyant and non-buoyant releases

- Flat and complex terrain

- Dry or wet deposition

- Gravitational settling of particles

- Short- and long-range transport 
- Fixed winds, surface or profile observations, or gridded meteorological input

- Puff sampling (i.e., receptors)

SCIPUFF can:

- Provide estimates of the uncertainty in the concentration field

- Perform accurate treatment of wind shear

- Merge puffs in addition to splitting them using an efficient adaptive multi-grid scheme

- Use an efficient adaptive time-stepping scheme

- Utilize static puffs near the source to reduce computation time

- Provide flexible output displays with color contour plots of concentration and probabilities of exceeding user-specified concentrations. 


\section{Running the Smokes Dispersion Web Interface}

\section{Setup}

To acquire and use HPAC, you must agree to certain conditions. For this reason, HPAC must be requested directly from DTRA. By this means DTRA continues to be solely responsible for distribution of HPAC software. ERDC/CERL developed the web interface and the fog oil characterization demonstration. These, plus the setup directions are available from ERDC via CDROM. Once HPAC is installed, you need to copy the HPAC2 directory (and contents) from the distribution CDROM to your hard disk. Since each implementation location has its own firewall regulations, making the web page available over your local area network (LAN) is a matter you or your local user group needs to address with the information management personnel.

Once HPAC and the files are in place, double click on the file named "Welcome.htm" in the HPAC2 directory.

\section{User Interface and Output}

The web browser will display an introductory page (Figure 1). The options available include:

1. Run an example fog oil demonstration (intended to be modified per your needs)

2. Run the entire HPAC capability

3. Translate the output of the HPAC run (e.g., integrated vector file of concentration levels) into a standard GIS format (i.e., shapefiles for ESRI's ArcView GIS.) 


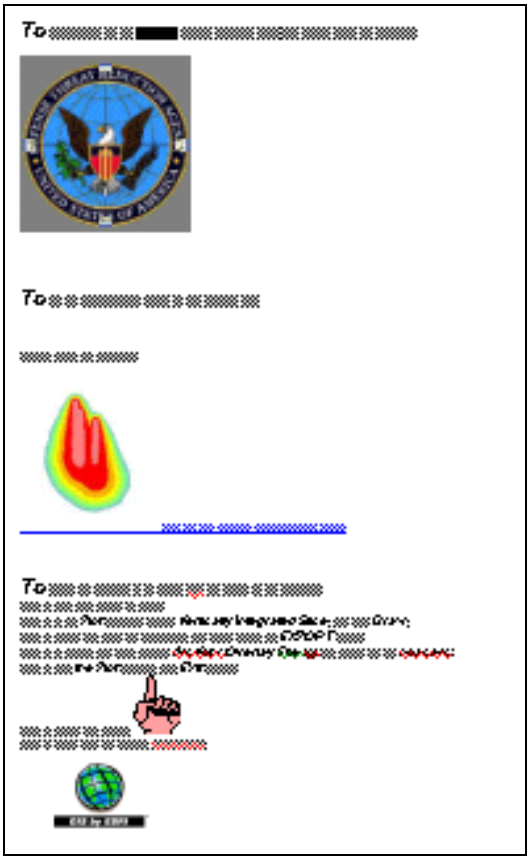

Figure 1. Web introductory page.

If you choose to run the fog oil demonstration, you will be presented with the initial HPAC input page (Figure 2) with example inputs.

If you wish to run a scenario at your local installation, click on the "Edit Project" button in Figure 2. Once this is done, the other boxes are available for changes. For detailed information, refer to the complete HPAC User Guide (DSWA 1999).

In general, you may to want to edit the following:

- Domain (i.e., your installation location and the extent of the analysis). Plumes that go beyond this extent will be cut off.

- Time (must be in the future).

- Release. These are the locations of the training actions. More can be added than the locations illustrated.

- Weather. Various options are available. The one illustrated here (and available on the HPAC distribution disk) is to use the historical climatological data. DTRA can also provide you with access to near real time weather data. It is within the weather window that real time weather as well as the terrain and land cover options are accepted. 
You normally will not want to edit the following:

- Material. Fog Oil is the default and has already been described for purposes of running HPAC.

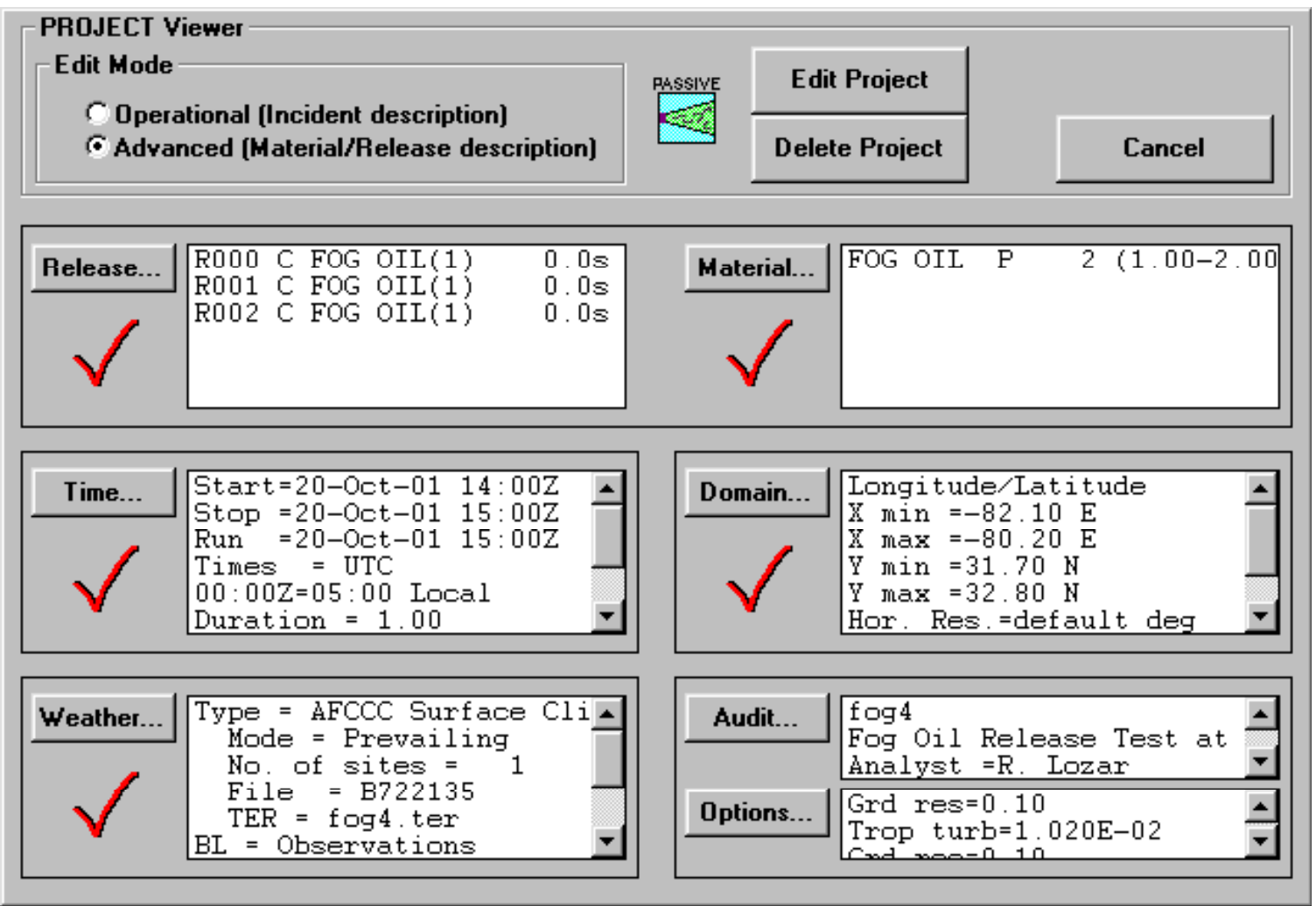

Figure 2. HPAC fog oil initial (project) screen.

After you have entered new characteristics, a button will appear that says "Run Project." When you click this button, the system will warn you that this will change the project. This is what you want to do. After a few seconds, you will be presented with a results screen (Figure 3). To see these mapped results you:

- MUST press the "DRAW" button.

- Under Plot Choice, choose "Vertically Integrated Slice."

- Under "Plot Options," "Maps," choose "details," and pick labeling options appropriate for the session. 


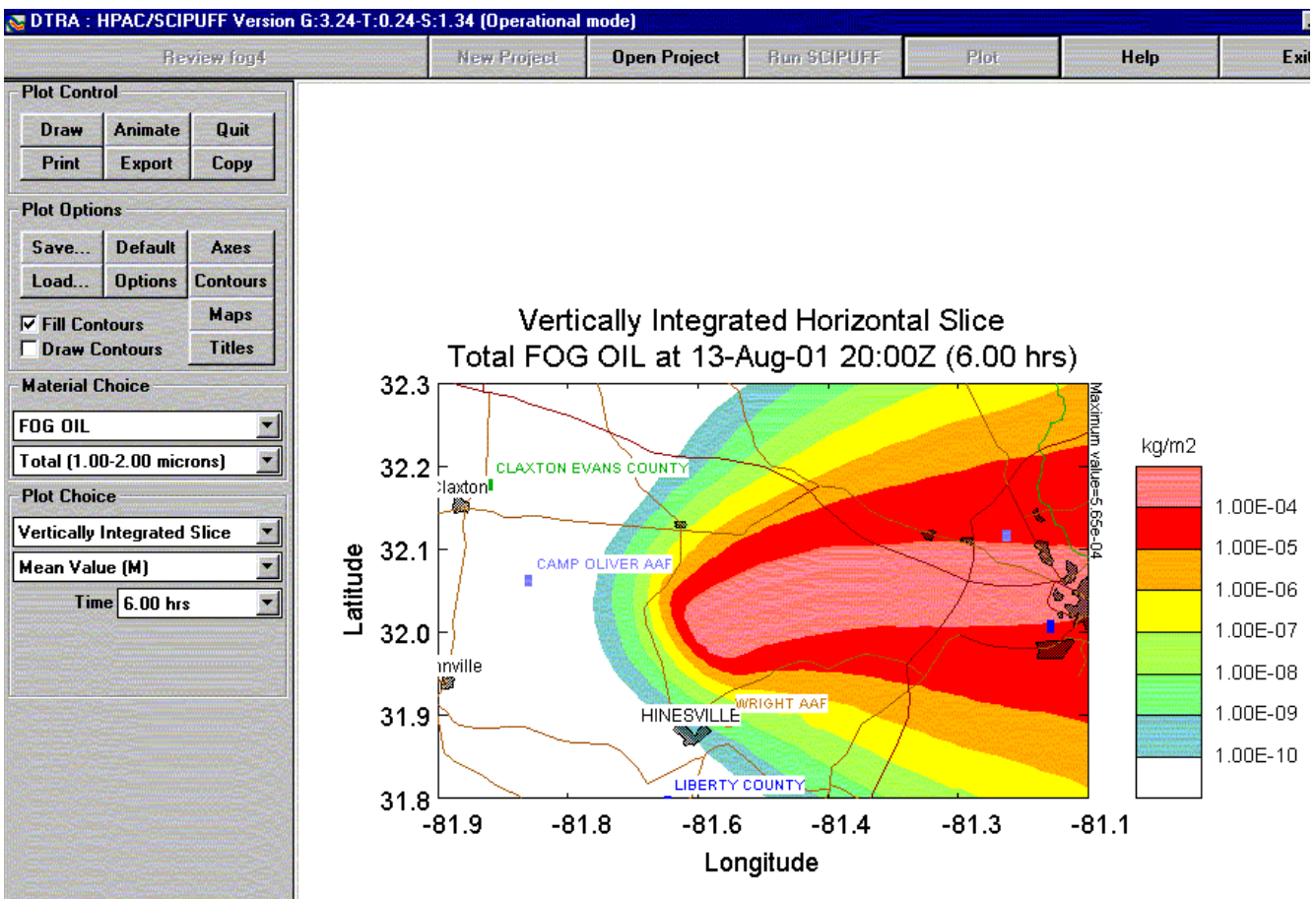

Figure 3. Results screen.

The many other options available in HPAC at this point are well explained in the User's Guide. Figure 4 shows a standard example for a run at Fort Benning, GA. Figure 5 shows that the output (.bmp format) can be translated into a movie file that can be played within a media player. This is accomplished by pressing the "Animate" button in Figure 3.

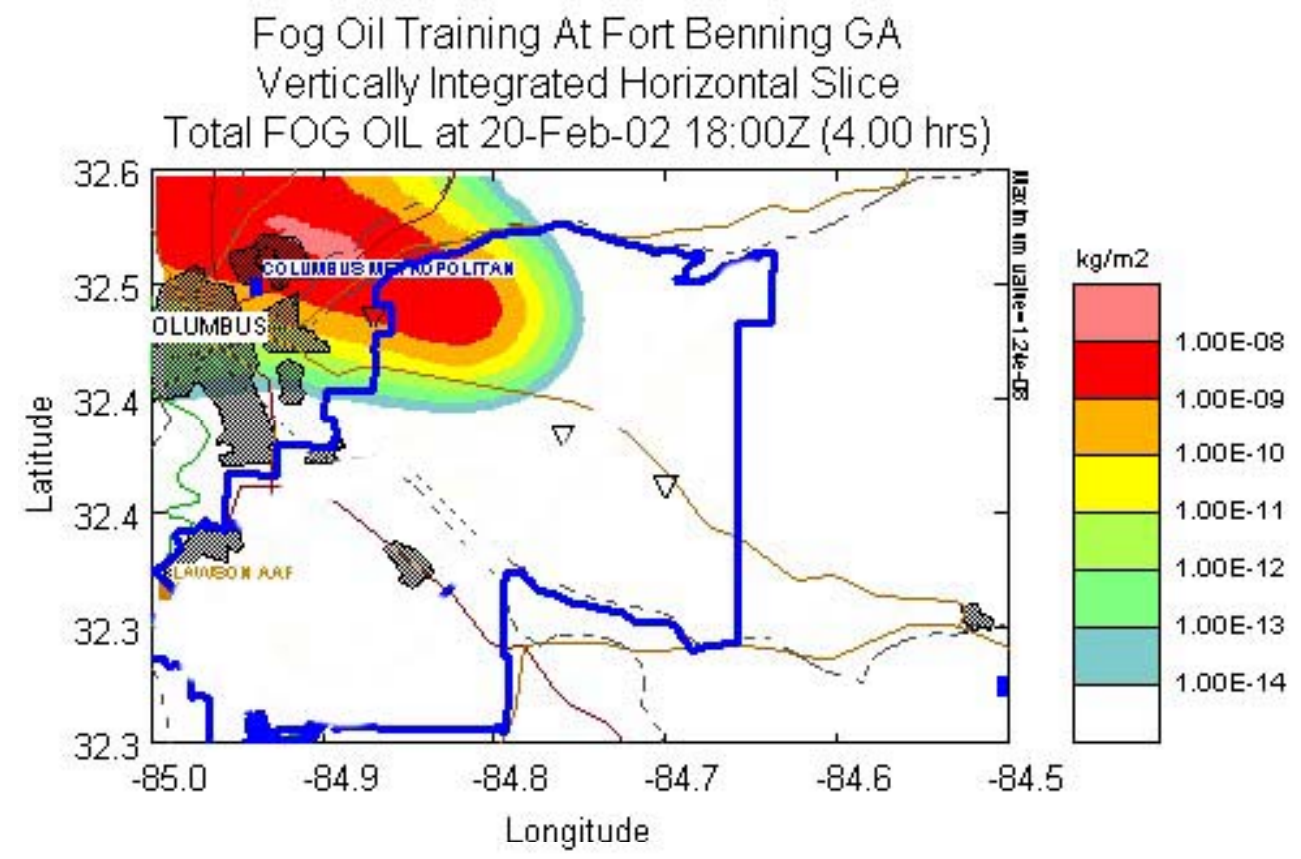

Figure 4. Example at Fort Benning, GA. 

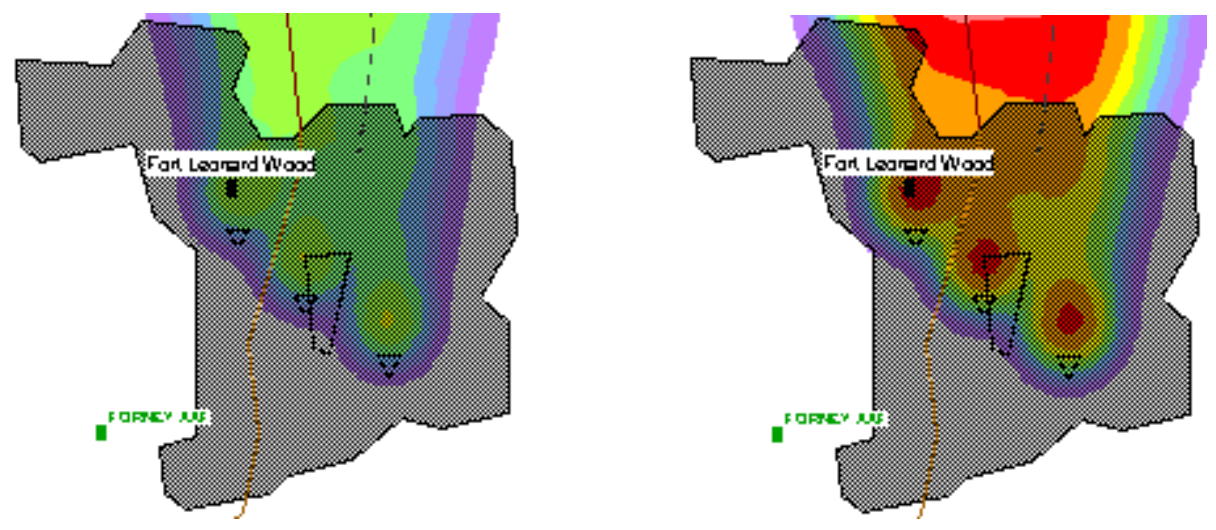

Figure 5. Animation of release over time is an option.

\section{Output Integration With the Installation GIS}

It is likely that you will want to save the HPAC contour output in your GIS. To do this:

1. In Figure 3 in the Plot Choice Window, Select Vertically Integrated Slice, and then Draw.

2. On the Results Screen (also Figure 3), press the Export button and choose ArcView Overlay File and Name the file hpacarc.

Warning: this is not yet an ESRI shapefile (.shp) format.

3. To generate an ArcView .shp format file, Quit the Plot window, then Exit HPAC.

4. On the Introductory Web Page (Figure 1), press the "Pointing finger" button. This tells the system to prepare to use the translator, already provided from the CDROM.

5. Press the "ESRI World" button to generate a shape file. The output will be located in your HPAC2 directory under the name hpacarc.shp. You need to rename or move this file before you carry out this procedure again otherwise it will be overwritten.

6. View the new .shp file through your GIS. Alternatively, you can establish ArcExplorer on your computer and view it with this program. (ArcExplorer is available on the web at:

http://www.esri.com/software/arcexplorer/index.html) 
An example of HPAC contours in an ArcExplorer GIS configuration is given in Figure 6.

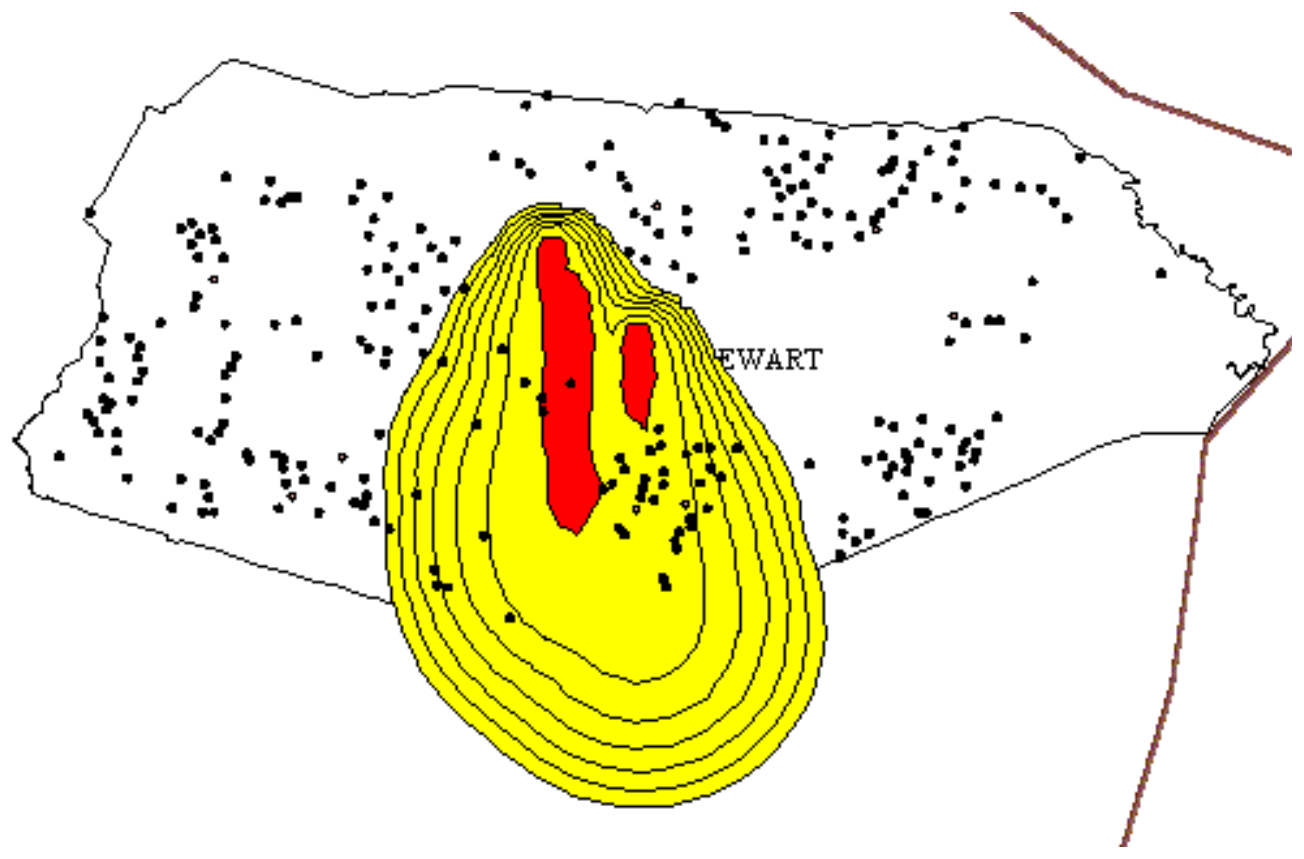

Figure 6. Integrated into GIS format with TES locations at Fort Stewart, GA. 


\section{Summary and Recommendations}

Though the military use of obscurants is thousands of years old, their application has recently been increasing. Concurrent with this increase is a need to know exactly how they (particularly the most common, fog oil) disperse in the atmosphere to ensure that training at military installations follows laws and regulations regarding sensitive species management. Research carried out through funding from SERDP and direct Army conservation research resulted in the development of a web based fog oil modeling capability. The HPAC modeling program is the underlying software used. It runs on a desktop computer under the MS Windows ${ }^{\circledR}$ operating system. ERDC has implemented an HTML web interface so that the fog oil modeling capability is easy to use and can be accessed across a local area network.

HPAC assesses the dispersion of atmospheric concentrations downwind from point sources. The modeling is based on a Second-order Closure Integrated PUFF model (SCIPUFF) routine that can adjust for terrain and land cover conditions. It is a LaGrangian puff dispersion model that uses a collection of Gaussian puffs to represent an arbitrary, three-dimensional time-dependent concentration. SCIPUFF results have been well field tested, and can be used as an alternative EPA model for regulatory issues.

The purpose of developing a web interface for modeling fog oil dispersion during training is to make the results available to the installation trainer immediately before a training exercise is planned, thus ensuring an acceptable level of exposure on any known endangered species. If the model predicts an unacceptable exposure level, the trainer has the opportunity to modify the training location or time to keep the exposure within levels acceptable to local regulatory agencies (e.g., the U.S. Fish and Wildlife Service).

Setup requires access to two CDROMS: HPAC from DTRA and the Fog Oil configuration from ERDC/CERL. Implementation is inexpensive and easy. Access is through a web browser that uses icons to call up the programs that formulate and run the models. Output can be tailored to the users needs, including the translation of HPAC output contours to a standard GIS format (i.e., ArcView .shp file) that can be used in the installation's local GIS configuration. 
The HPAC Model has been implemented in a web setting and will accept real time user input. Within minutes after submission, the user will receive a map of the distribution concentrations (Figure 4). With the implementation of this modeling, a user has the ability to apply some of the most sophisticated modeling capabilities available toward his land management requirements.

This research was limited to clearly stated tasks. However, some additional upgrades would be useful. A closer relationship could be established between the inputs and web input. A more integrated connection between the generation of the SO contours and evaluation against known TES locations would make the procedure even more user friendly. Configurations to answer more detailed questions can be implemented. Modifying the inputs to run these models at the micro scale would also have value.

With this powerful new tool, a practitioner can now quickly and inexpensively carry out tasks that were nearly impossible a decade ago. The resources have been provided to allow the development and integration of advanced technologies to render the best scientific answers possible. 


\section{References}

Defense Special Weapons Agency. 1999. HPAC Version 3.2 Users Guide, HPAC-UGUIDE-01 -URAC0, SAIC, October, 1999.

Driver, C. J.; M. W. Ligotke; W. G. Landis; J. L. Downs; B. L. Tiller; E. B. Moore Jr.; and D. A. Cataldo. 1993. Environmental and Health Effects Review for Obscurant Graphite Flakes. ERDEC-CR-056. Final Report. Pacific Northwest National Laboratory, Richland, WA.

Driver, Crystal, Michael Ligotke, Heather Galloway-Gorby, Gary Dennis, Keturah Reinbold, and Harold Balbach. 2002. Acute Inhalation Toxicity of Fog Oil Smoke in the Red-winged Blackbird, a Size-specific Inhalation Surrogate for the Red-cockaded Woodpecker, ERDC/CERL Technical Report TR-02-6/ADA399210, February 2002, Engineer Research and Development Center/Construction Engineering Research Laboratory.

Field Manual (FM) 3-50, Smoke Operations, Headquarters, Department of the Army, Washington, DC, December 1990.

Getz, Lowell L.; Keturah A. Reinbold; David J. Tazik; Timothy J. Hayden; and Debra M. Cassels. 1996. Preliminary Assessment of the Potential Impact of Fog Oil Smoke on Selected Threatened and Endangered Species, Technical Report 96/38/ADA306219, U.S. Army Corps of Engineers Construction Engineering Research Laboratory, January 1996.

Lozar, R. C. and M. J. Hanson. 1997. "Dispersion Model and GIS Comparison/Evaluation in Support of TES Smokes and Obscurant Impacts," CERL Internal Report (Unpublished), 20 January 1997.

Lozar, R. and K. Reinbold. 2001. "Modeling Environmental Impacts over the Internet: Smoke Dispersion Prototype," International Journal of Applied Science and Computations, Volume 8 Number 2, August 2001.

Sykes, R. I.; W. S. Lewellen; and S. F. Parker. 1986. "A Gaussian Plume Model of Atmospheric Dispersion Based on Second-Order Closure," J. Clim. Appl. Met., 25, 322-331 (1986).

Sykes, R. I.; S. F. Parker; D. S. Henn; and W. S. Lewellen. 1993. "Numerical Simulation of ANATEX Tracer Data Using a Turbulence Closure Model for Long-Range Dispersion," J. Appl. Met., 32, 929-947 (1993).

Sykes, R. I.; D. S. Henn; S. F. Parker; and R. S. Gabruk. 1996. "SCIPUFF - A generalized hazard dispersion model." Ninth Joint Conference on the Applications of Air Pollution Meteorology with $A \& W M A$, American Met. Soc.

Sykes, R. I. and R. S. Gabruk. 1997. "A second-order closure model for the effect of averaging time on turbulent plume dispersion." J. Appl. Met., 36, 165-184. 
Sykes, R. I.; S. F. Parker; D. S. Henn; C. P. Cerasoli; and L. P. Santos. 1998. PC-SCIPUFF Version 1.1PD.1 Technical Documentation. ARAP Report No. 718. Titan Corporation, Titan Research \& Technology Division, ARAP Group, P.O. Box 2229, Princeton, NJ, 08543-2229.

Sykes, R. I.; C. P. Cerasoli; and D. S. Henn. 1999. "The representation of dynamic flow effects in a Lagrangian puff dispersion model.” J. Haz. Mat., 64, 223-247. 


\section{Acronyms and Abbreviations}

$\begin{array}{ll}\text { CERL } & \text { Construction Engineering Research Laboratory } \\ \text { DSWA } & \text { Defense Special Weapons Agency } \\ \text { DTRA } & \text { Defense Threat Reduction Agency } \\ \text { DoD } & \text { Department of Defense } \\ \text { DOE } & \text { Department of Energy } \\ \text { EPA } & \text { Environmental Protection Agency } \\ \text { ERDC } & \text { U.S. Army Engineer Research and Development Center } \\ \text { ESRI } & \text { A company supplying GIS software } \\ \text { FM } & \text { Field Manual } \\ \text { GIS } & \text { Geographic Information Systems } \\ \text { HPAC } & \text { Hazard Prediction and Assessment Capability } \\ \text { HTML } & \text { HyperText Markup Language } \\ \text { http } & \text { Hypertext Transfer Protocol } \\ \text { LAN } & \text { Local Area Network } \\ \text { MET } & \text { Meteorological } \\ \text { SCIPUFF } & \text { Second-order Closure Integrated PUFF } \\ \text { SERDP } & \text { Strategic Environmental Research and Development Program } \\ \text { SO } & \text { Smokes and Obscurants } \\ \text { TES } & \text { Threatened and Endangered Species } \\ \end{array}$




\section{CERL Distribution}

Chief of Engineers

ATTN: CEHEC-IM-LH (2)

Engineer Research and Development Center (Libraries)

ATTN: ERDC, Vicksburg, MS

ATTN: Cold Regions Research, Hanover, NH

ATTN: Topographic Engineering Center, Alexandria, VA

SERDP (2)

USACE

ATTN: CERD-ZA

Defense Tech Info Center 22304

ATTN: DTIC-O 


\begin{tabular}{|c|c|c|}
\hline $\begin{array}{l}\text { 1. REPORT DATE (DD-MM-YYYY) } \\
08-2002 \\
\end{array}$ & 2. REPORT TYPE & 3. DATES COVERED (From - To) \\
\hline \multirow{3}{*}{\multicolumn{2}{|c|}{$\begin{array}{l}\text { 4. TITLE AND SUBTITLE } \\
\text { Web Interface for Modeling Fog Oil Dispersion During Training }\end{array}$}} & 5a. CONTRACT NUMBER \\
\hline & & 5b. GRANT NUMBER \\
\hline & & 5c. PROGRAM ELEMENT NUMBER \\
\hline \multirow{3}{*}{\multicolumn{2}{|c|}{$\begin{array}{l}\text { 6. AUTHOR(S) } \\
\text { Robert C. Lozar }\end{array}$}} & $\begin{array}{l}\text { 5d. PROJECT NUMBER } \\
\text { SERDP and 622720A896 }\end{array}$ \\
\hline & & $\begin{array}{l}\text { 5e. TASK NUMBER } \\
\text { CS-507; CNN-TO21 }\end{array}$ \\
\hline & & 5f. WORK UNIT NUMBER \\
\hline \multicolumn{2}{|c|}{$\begin{array}{l}\text { 7. PERFORMING ORGANIZATION NAME(S) AND ADDRESS(ES) } \\
\text { U.S. Army Engneer Research and Development Center (ERDC) } \\
\text { Construction Engineering Research Laboratory (CERL) } \\
\text { PO Box } 9005 \\
\text { Champaign, IL } 61826-9005\end{array}$} & $\begin{array}{l}\text { 8. PERFORMING ORGANIZATION REPORT } \\
\text { NUMBER } \\
\text { ERDC/CERL TR-02-16 }\end{array}$ \\
\hline \multicolumn{2}{|c|}{ 9. SPONSORING / MONITORING AGENCY NAME(S) AND ADDRESS(ES) } & 10. SPONSOR/MONITOR'S ACRONYM(S) \\
\hline \multirow{2}{*}{\multicolumn{2}{|c|}{$\begin{array}{ll}\text { Strategic Environmental Research and } & \text { U.S. Army Corps of Engineers } \\
\text { Development Program } & \text { 441 G Street, NW } \\
901 \text { N. Stuart Street, Suite 303 } & \text { Washington, DC 20314-1000 } \\
\text { Arlington, VA 22203-1853 } & \end{array}$}} & Program Manager \\
\hline & & $\begin{array}{l}\text { 11. SPONSOR/MONITOR'S REPORT } \\
\text { NUMBER(S) }\end{array}$ \\
\hline
\end{tabular}

12. DISTRIBUTION / AVAILABILITY STATEMENT

Approved for public release; distribution is unlimited.

\section{SUPPLEMENTARY NOTES}

Copies are available from the National Technical Information Service, 5285 Port Royal Road, Springfield, VA 22161.

\section{ABSTRACT}

Predicting the dispersion of military camouflage training materials — Smokes and Obscurants (SO) — is a rapidly improving science. The Defense Threat Reduction Agency (DTRA) developed the Hazard Prediction and Assessment Capability (HPAC), a software package that allows the modeling of the dispersion of several potentially detrimental materials. ERDC/CERL characterized the most commonly used SO material, fog oil in HPAC terminology, to predict the SO dispersion characteristics in various training scenarios that might have an effect on Threatened and Endangered Species (TES) at DoD installations. To make the configuration more user friendly, the researchers implemented an initial web-interface version of HPAC with a modifiable fog-oil component that can be applied at any installation in the world. By this method, an installation SO trainer can plan the location and time of fog oil training activities and is able to predict the degree to which various areas will be effected, particularly important in ensuring the appropriate management of TES on a DoD installation. This document discusses the development of obscurants, the scientific basis for the HPAC modeling, the fog oil web implementation, its use, example results available from the modeling and how it interfaces with standard installation Geographical Information Systems (GIS).

\section{SUBJECT TERMS}

Hazard Prediction Assessment Capability (HPAC), smoke and obscurants, threatened and endangered species, Stategic Environmental Research and Development Program (SERDP), computer based modeling, military training

\begin{tabular}{|c|c|c|c|c|c|}
\hline \multicolumn{3}{|c|}{ 16. SECURITY CLASSIFICATION OF: } & \multirow{2}{*}{$\begin{array}{l}\text { 17. LIMITATION } \\
\text { OF ABSTRACT } \\
\text { SAR }\end{array}$} & \multirow{2}{*}{$\begin{array}{l}\text { 18. NUMBER } \\
\text { OF PAGES } \\
\\
25\end{array}$} & 19a. NAME OF RESPONSIBLE PERSON \\
\hline $\begin{array}{l}\text { a. REPORT } \\
\text { Unclassified }\end{array}$ & $\begin{array}{l}\text { b. ABSTRACT } \\
\text { Unclassified }\end{array}$ & $\begin{array}{l}\text { c. THIS PAGE } \\
\text { Unclassified }\end{array}$ & & & $\begin{array}{l}\text { 19b. TELEPHONE NUMBER (in- } \\
\text { clude area code) } \\
217-352-6511 \text { ext } 6367\end{array}$ \\
\hline
\end{tabular}

